\title{
MUSEUS E SUSTENTABILIDADE
} AMBIENTAL

\author{
M. C. Furtado Mendes ${ }^{1}$
}

\section{Introdução}

A questão ambiental que há alguns anos se tornou um problema grave para a sobrevivência de todos os seres vivos, é reflexo do desenvolvimento industrial que, embora tenha trazido a modernização e contribuído para o bem estar de todos, não teve em conta o impacto que a utilização das energias de origem poluentes e finitas iriam causar num futuro que chegou sem que disso praticamente se tivesse dado conta.

O património natural e o cultural necessitam de estar integrados num ambiente apropriado com condições especificas para cada caso concreto de forma a que a sua preservação e durabilidade se prolongue. Existem fatores que interferem direta ou indiretamente na sua degradação, que podem produzir efeitos negativos a um ritmo mais ou menos acelerado. Estes estão sobejamente identificados, face à ampla informação disponível sobre os cuidados de prevenção a ter em conta, por exemplo em termos ambientais, apenas será necessário criar as condições apropriadas em cada local e para cada tipo de acervo. Desta forma, estaremos a contribuir para o prolongamento da vida do património que as gerações atuais e vindouras terão ao seu dispor, permitindo-

\footnotetext{
${ }^{1}$ PhD em Museologia e Professor na Universidade Lusófona de Humanidades e Tecnologias, em Lisboa; manuelcfurtadomendes@gmail.com
} 
Ihes a partir do seu bom estado de conservação obter um amplo conhecimento da história da humanidade.

Face aos sinais degradação ambiental que se foram tornando evidentes, verificou-se que as preocupações inerentes ganharam contornos de grande empenho na estabilização do meio ambiente e nesse sentido começaram a ser promovidos debates mundiais de onde surgiram, na década de sessenta do século passado com o desenvolvimento da ecologia, as diversas Cartas, Convenções e Recomendações Internacionais, que assim se constituem como as primeiras tentativas organizadas a nível mundial para a preservação do património natural.

São exemplos dessa preocupação do Mundo com o ambiente, os documentos produzidos e emitidos no seio da ONU/UNESCO, ICOMOS e Conselho da Europa, dos quais aqui destacamos alguns:

No ano de 1971 foi assinada a "Convenção Relativa às zonas húmidas e de importância internacional" (UNESCO) que reconhecia a interdependência do Ser Humano com o seu meio ambiente;

Em 1972, foi elaborada e assinada a "Convenção do Património Mundial, Cultural e Natural" da UNESCO. Nesta Convenção assumiu-se o património natural a par do património cultural, admitindo-se que "devem ser considerados na sua globalidade como um todo homogéneo";

Em 1976, o ICOMOS (Conselho Internacional de Monumentos e Sítios) manifesta na "Carta de Turismo Cultural" a preocupação com o entorno do Ser Humano e dos monumentos e, na "Carta de Nairobi", produzida pela UNESCO nesse mesmo ano, definia-se como "ambiência" dos conjuntos históricos ou tradicionais, "o quadro natural ou construído que influi na perceção desses conjuntos" e reiterou-se a necessidade de incluir o entorno nas medidas de preservação patrimonial;

Em 1976, o Conselho da Europa produziu o chamado "Apelo de Granada" sobre a arquitetura rural no ordenamento do Território. Este documento vai ainda mais longe que os anteriores e considera que a paisagem rural está ameaçada de extinção. A excessiva exploração da natureza, nomeadamente pela 
industrialização, traz como consequências "desequilíbrios ecológicos perigosos" que provocam alterações estruturais dos "traços característicos da paisagem como sebes, declives, pequenos bosques, ribeiros, etc."

Em 1997, a ONU emite a "Declaração sobre as Responsabilidades das Gerações Presentes para com as Gerações Futuras", que tem a ver a necessidade de preservação do ambiente natural, estendendo-o à escala planetária. Revestindo-se este documento de extrema importância ao chamar a atenção para a preservação ambiental como condição determinante para a sobrevivência do ser humano enquanto espécie. Já não estamos apenas perante a necessidade de preservar os vestígios culturais do Ser Humano, mas assegurar a nossa continuidade na Terra, a das gerações futuras e das restantes espécies.

A Declaração sobre as responsabilidades das gerações presentes para com as gerações futuras, considera que a destruição do meio ambiente constitui uma ameaça para a sobrevivência das gerações futuras conforme está patente nos seus artigos 4.ㅇ e 5.을

\section{"Article 4 - Préservation de la vie sur Terre}

Les générations présentes ont la responsabilité de léguer aux générations futures une Terre qui ne soit pas un jour irrémédiablement endommagée par l'activité humaine. Chaque génération, recevant temporairement la Terre en héritage, veillera à utiliser raisonnablement les ressources naturelles et à faire en sorte que la vie ne soit pas compromise par des modifications nocives des écosystèmes et que le progrès scientifique et technique dans tous les domaines ne nuise pas à la vie sur Terre.

\section{Article 5 - Protection de l'environnement}

1. Afin que les générations futures puissent bénéficier de la richesse des écosystèmes de la Terre, les générations présentes devraient oeuvrer pour un 
développement durable et préserver les conditions de la vie, et notamment la qualité et l'intégrité de l'environnement."

Referimos ainda, neste olhar sobre as recomendações e diretivas internacionais, a "Declaração Universal Sobre a Diversidade Cultural" (UNESCO, 2001) que considera a biodiversidade e o património natural como fazendo parte da diversidade cultural, indo ao encontro da necessidade de uma conservação integrada.

Estes documentos aqui muito resumidamente referidos testemunham e contextualizam as preocupações ambientais sobretudo as que recaem sobre o património natural, situação que naturalmente se articula com as inquietações com o património cultural, o trabalho dos Museus e a reflexão sobre a Museologia.

Parece-nos também que os Museus enquanto instituições que têm uma função preservacionista - independentemente de se tratar de Museus que lidam com coleções materiais ou de Museus que lidam com o social e a comunidade - devem servir de exemplo na utilização de todos os meios técnicos disponíveis nomeadamente nas áreas da eficiência energética e das energias de origens limpas e renováveis, como uma forma eficiente de contribuir para a sustentabilidade ambiental e económica do nosso Planeta.

Por todas estas preocupações mundiais referidas, entendemos que os edifícios onde funcionam Museus devem estar

\footnotetext{
${ }^{2}$ Tradução livre: “Artigo 4.‥ Preservação da vida na Terra. As gerações presentes têm a responsabilidade de legar às gerações futuras uma Terra que não fique um dia irremediavelmente estragada pela atividade humana. Cada geração, recebendo temporariamente a Terra em herança, zelará pela utilização razoável dos recursos naturais e de maneira que a vida não seja comprometida por modificações nocivas dos ecossistemas e que o progresso científico e técnico em todos os domínios não prejudique a vida na Terra; Artigo 5.o. Proteção do ambiente. 1. Para que as gerações futuras possam beneficiar da riqueza dos ecossistemas da Terra, as gerações presentes deveriam trabalhar por um desenvolvimento durável e preservar as condições da vida, nomeadamente a qualidade e a integridade do ambiente."
} 
ou virem a ser equipados a curto prazo, com os meios técnicos disponíveis e adequados a cada caso concreto, nomeadamente no que se refere à implementação de condições por forma a que estes contribuam de forma ativa para o equilíbrio ambiental que se deseja e se tornou indispensável ao bem-estar de todos.

\section{Tipos de edifícios onde funcionam Museus,}

Os edifícios onde funcionam Museus têm origem e tipo de construção bastante diversificada, que vão desde o aproveitamento de património histórico construído com alguns séculos de existência, passando por edifícios comuns adaptados, até aos construídos de raiz para esta função.

Assim, temos os denominados Museus nacionais que são por excelência o símbolo da identidade cultural em qualquer País e, por essa razão contêm, as mais importantes e/ou valiosas coleções nacionais. Encontram-se normalmente instalados em edifícios históricos de grande valor arquitetónico.

Temos também a construção de grandes complexos culturais que se multiplicaram por todo o mundo tendo mesmo constituído uma das orientações mais marcantes verificadas no final do século passado, como por exemplo, o recente Museu Guggenhein de Bilbau. Este tipo de equipamento cultural possui normalmente características adequadas para a promoção da multiculturalidade mas também da multifuncionalidade e tem origem muito antiga, basta lembrarmo-nos do histórico Museu de Alexandria que incluía a Biblioteca, Academia, Observatório Astronómico e Universidade.

São normalmente edifícios imponentes, construídos em locais estratégicos pelo poder central dos vários países e destinados a responder às necessidades de desenvolvimento cultural das comunidades que os podem frequentar. Esta construção constitui de um modo geral, uma oportunidade para o poder central e/ou local, o exibir como símbolo do seu poder.

Por fim, referimos também os Museus locais e/ou regionais e mesmo casas de memória que existem em grande quantidade por todo o mundo e tendo uma função muito importante junto das suas 
comunidades, uma vez que é um equipamento cujas características de proximidade às populações permite, nalgumas situações, que estas, com os seus conhecimentos, se envolvam com maior ou menor participação para poderem salvaguardar os seus patrimónios. Em 1960 foi criado um Comité Internacional do ICOM International Committee for Regional Museums (ICR), cuja sua função principal se insere no apoio ao desenvolvimento ativo, em todo o mundo, desta tipologia de Museus.

Verifica-se assim uma grande diversidade de edifícios onde podem ser instalados os diversos tipos de Museus, bem como diversidade das suas características físicas e qualidade construtiva muito diversas, o que é uma situação normal, pois os critérios utilizados para a sua implementação são muito vastos e têm em conta variáveis e condicionantes influentes, onde uma delas será certamente o seu custo em termos imediatos.

Assim, apesar da diversidade de construções que albergam Museus, muito raramente se teve em conta a instalação de qualquer tipo de equipamento com o objetivo e função de poderem contribuir para a preservação ambiental através da utilização de tecnologias apropriadas para esse efeito e disponíveis há anos.

Nos tempos atuais em que o ambiente é vital para o equilíbrio saudável de todos os seres vivos e para a manutenção da biodiversidade, não nos parece que possamos deixar de insistir ou mesmo exigir de todos nós e das entidades que tutelam e/ou gerem estes equipamentos para que a falta de sensibilidade na implementação e utilização de fontes energéticas de origem renovável e limpa seja colmatada a curto prazo sem que seja entendida como um custo mas sim como um investimento imprescindível para o presente e futuro da humanidade.

Isto porque entendemos, que uma das principais soluções que pode e irá contribuir fortemente para a sustentabilidade ambiental e mesmo económica destes equipamentos culturais, é a captação e utilização das energias renováveis e limpas cujo elevado desenvolvimento técnico permite aplicações adaptáveis e 
enquadráveis para todos os edifícios de Museus existentes ou a edificar.

Cumulativamente com a utilização destas fontes energéticas é importante que os próprios edifícios sejam ou estejam dotados das melhores características de localização e físicas no que se refere à sua orientação solar e aos materiais utilizados, porque do cumprimento ou não destas premissas depende a sua boa ou menos boa eficiência energética, que se reflete diretamente nos consumos energéticos requeridos para a obtenção das condições de conforto adequadas para os diferentes tipos de acervos e frequentadores e/ou utilizadores destes equipamentos.

Com já foi referido, muitos dos edifícios onde funcionam Museus possuem um elevado valor histórico e patrimonial, sendo mesmo uma valiosa herança deixada por outras gerações e cuja preservação é da responsabilidade da geração atual. Trata-se, na grande maioria, de construções efetuadas em épocas distantes em que os materiais e as tecnologias usadas eram bem diferentes das que atualmente estão disponíveis, o que, naturalmente, provoca um desajuste face às necessidades e exigências atuais.

Para que as suas funcionalidades se ajustem à obtenção dos vários tipos de conforto (diferentes acervos e humano) que as novas tecnologias e alguns materiais de isolamento e/ou revestimento que caracterizam as atuais construções proporcionam, há que criar ou ir criando essas condições e executando as obras necessárias com rigor e de acordo com o que cada caso concreto exigir uma vez que são soluções eficazes e necessárias para a resolução dos problemas decorrentes do seu envelhecimento que se observam nas deteriorações de revestimentos ou mesmo em termos estruturais. Assim, conservar, remodelar e ampliar estes edifícios, são soluções naturais para que a cada momento da sua vida se introduzam as inovações que proporcionem as melhores condições de conforto tendo também em vista a redução dos consumos energéticos.

Por forma a não descurar a preservação ambiental, quando é tomada a decisão de construir um novo edifício destinado a Museu, 
devem ser tidas em consideração algumas questões para que estes edifícios se possam enquadrar dentro de parâmetros ecossustentáveis, originando assim a redução dos seus custos operacionais. Estes parâmetros relacionam-se com a implementação de características técnicas que permitam a redução do consumo de energia seja qual for a sua origem, a redução do consumo de água, a redução da produção de lixo e, só depois o incremento do número de visitantes/utilizadores com a oferta de eventos culturais atrativos e de elevada qualidade.

Normalmente, o local para a construção de um novo Museu está sujeito às disponibilidades de terrenos com as dimensões adequadas ao que se pretende construir. Daí resultar, por vezes, que a sua localização no que se refere à exposição solar, luminosidade natural, arejamento, poluição ambiental, existência de zonas verdes e boas acessibilidades, possa não ser a ideal para se garantir à partida, não só a obtenção de um bom desempenho energético sem custos muito elevados, mas também, de todas as condições que irão permitir a atração de visitantes/utilizadores destes espaços. A atratividade do Museu certamente não terá a ver apenas com os seus conteúdos/acervos mas também com toda a sua envolvência natural.

Estes dois fatores têm uma enorme importância e, por isso, devem ser usados em simultâneo para assim se obter um bom resultado global. Ou seja, um Museu deve estar num local naturalmente atraente e com boas acessibilidades, quer através de transportes públicos, quer por transporte privado. Deve garantir-se uma ligação entre a natureza envolvente, o edifício e os conteúdos do edifício que, no seu conjunto, atraiam público de todas as idades para que desta forma, a cultura possa ser divulgada e apreendida por todos.

Quanto ao edifício em si, deve ser tido em conta o fim específico a que se destina. Se este se destina apenas a Museu, ou se é para nele funcionarem outras atividades culturais e sendo este caso, devem observar-se as diversas valências, a capacidade pretendida em termos de áreas expositivas, auditórios e serviços de 
apoio, o seu "lay-out» ${ }^{3}$ interior e toda a sua envolvência e enquadramento com o exterior.

A construção do edifício quer se trate da estrutura, materiais de enchimento ou de revestimento, deve contemplar a existência de uma adequada resistência ao fogo, tratamento térmico e acústico de todos os seus compartimentos e iluminação e ventilação naturais, bem como a existência da exploração de uma ou mais fontes de energias renováveis e limpas.

Havendo a preocupação de efetuar a construção incluindo os parâmetros atrás referidos, o edifício torna-se detentor de uma eficiência energética elevada e o seu consumo energético descerá substancialmente. Podemos referir para consulta uma recente e interessante "publicação" ${ }^{4}$, que trata com profundidade e rigor as diferentes e fundamentais fases que antecedem a construção e durante esta, instalação e funcionamento de Museus, incluindo estudos económicos, sendo que deste modo, estamos sem dúvida, a contribuir para uma sustentabilidade ambiental e económica cujos reflexos positivos se vão fazer sentir na melhor qualidade de vida do Ser Humano.

As poupanças nos consumos energéticos quaisquer que sejam as suas origens, vão cada vez mais tornar-se exigências vitais se quisermos contribuir para o equilíbrio ambiental que o nosso planeta tanto necessita.

Nesse sentido, o Parlamento Europeu, publicou recentemente uma nova Diretiva ( $n$ o 2010/31/CE, de 2010-06-19), cujo objetivo principal é que todos os edifícios a construir bem como os existentes, sejam dotados de características técnicas necessárias para que a sua eficiência energética proporcione um consumo energético zero, ou muito próximo deste valor, até ao ano de 2020

\footnotetext{
${ }^{3}$ Termo utilizado para designar a compartimentação interior num edifício ou numa parte deste

${ }^{4}$ Trata-se do livro: "PLANNING SUCCESSFUL museum building PROJECTS" de Walter L Crimm, Martha Morris, and L. Carole Wharton, editado no ano de 2009 pela AltaMira Press, USA.
} 
São evidentes e importantes os benefícios ambientais e consequentemente económicos quando se pode iniciar um projeto de raiz para implementação de um Museu num local geográfico criteriosamente escolhido e utilizando materiais adequados. Porque com estas premissas de extrema importância, surgem naturalmente, entre outros, os seguintes benefícios:

- redução do uso do ar condicionado;

redução das cargas de aquecimento e da contribuição da geração da energia elétrica, com a correspondente diminuição dos consumos;

- contribuição para a diminuição dos níveis de $\mathrm{CO}_{2}$ causados pela utilização de combustíveis fósseis, sempre que é usada a energia proveniente de fontes renováveis;

redução dos sintomas de doença reportados em pessoas que trabalhavam em edifícios com ar condicionado (conhecida como «síndroma dos edifícios doentes»);

melhoradas.

Alcançados estes objetivos resultam daí benefícios económicos de extrema importância. Há por isso lugar à redução de custos energéticos significativos, pelo que essas poupanças podem ser canalizadas para outros investimentos com benefícios adicionais nomeadamente:

- $\quad$ instalação de unidades de aquecimento e refrigeração de menores capacidades, reduzindo assim os custos da construção global de um edifício;

contribuição para a redução do défice comercial, uma vez que há necessidade de importar menos equipamentos e com menores capacidades para a produção de calor ou refrigeração;

diminuição da dependência económica de países com recursos económicos limitados. 
Podemos afirmar que o comportamento térmico de qualquer edifício é vital para que se obtenha um conforto saudável e por isso, a sua construção ou reabilitação deve ser sempre efetuada de forma a obterem-se os melhores resultados em termos da sua eficiência

\section{Energias renováveis nos edifícios de Museus}

Energias renováveis são todas as formas de energia cuja utilização é inferior à sua renovação sem que o ambiente se deteriore com a exploração mais ou menos intensiva.

Atualmente, a energia fornecida a partir da rede de distribuição pública já contém uma pequena percentagem de origem limpa e renovável proveniente de grandes centrais, nomeadamente hídricas, eólicas, térmicas que consomem vários tipos de resíduos e fotovoltaicas, no entanto esta produção está muito longe do que são as necessidades totais de consumo, e por isso, devem ser estudadas e implementadas outras soluções para que em qualquer local onde se encontrem edifícios de Museus se possam colocar mecanismos de captação transporte e produção de um ou mais tipos de energias renováveis para a sua utilização individual ou, havendo excesso de produção face ao consumo armazenando-a para utilização posterior ou mesmo colocá-la na rede de distribuição pública para consumo em outros locais.

Face às diferentes características e localizações dos edifícios onde estão instalados Museus, entendemos que as fontes energéticas de origem limpas a partir das quais estes podem captar as energias que necessitam e mais adaptáveis a estes equipamentos culturais, de uma forma independente e isolada e também pela sua facilidade de integração com valores de implementação acessíveis e comportáveis são as energias geotérmica de superfície, a solar térmica e a solar fotovoltaica.

Descrevendo sucintamente cada uma destas energias, temos a geotermia que é o ramo da Geofísica que tem a seu cargo o estudo da distribuição de calor no interior do nosso planeta. Por cada $100 \mathrm{~m}$ de profundidade, a Terra, sofre um aumento médio da 
sua temperatura de cerca de $3 \stackrel{\circ}{ } \mathrm{C}$. Este fenómeno está diretamente relacionado com processos de geodinâmica interna e com a absorção da radiação solar. O aproveitamento destas condições naturais permite obter energias renováveis, limpas, gratuita e não poluentes.

A poucas dezenas de centímetros de profundidade, o terreno que constitui a crosta terrestre encontra-se a uma temperatura estável, geralmente compreendida entre $5 \circ \mathrm{C}$ e $18 ㅇ ㅡ$, o que permite, com recurso à utilização de bombas de calor geotérmicas usar esse "calor geotérmico" em qualquer lugar que necessite de conforto térmico, usando recursos naturais.

Ao recorrer-se ao uso de bombas de calor geotérmico, estamos a utilizar um equipamento simples e económico, uma vez que apenas consomem cerca de $20 \%$ da energia que produzem, ou seja, por cada KWh de energia elétrica consumida produzem cerca de $5 \mathrm{KWh}$ de energia térmica. A instalação das bombas de calor geotérmico é feita ligando estas a um conjunto de tubos enterrados no solo, cujos diâmetros e comprimentos dependem das necessidades de energia, em cada caso concreto, dentro dos quais circula, em circuito fechado, um líquido, composto de uma mistura de água com glicol (líquido anticongelante) que tem a função de ir buscar a temperatura solicitada que se encontra armazenada no subsolo.

Esta permuta efetuada com o subsolo através da referida bomba de calor, permite a obtenção de aquecimento e arrefecimento para climatização de qualquer tipo de edifício ou compartimentos destes com diferentes funcionalidades. $\mathrm{Na}$ climatização dos diversos compartimentos dos edifícios recorre-se normalmente à utilização de pavimentos ou paredes radiantes (circulação de água quente em tubagem embebida nos pavimentos ou paredes de forma a que estes não fiquem mais do que 0,50 metros distanciados entre si), ventilo-convectores e sistema de condutas aéreas colocadas ao nível dos tetos ou, de pavimentos, contendo registos e grelhas por onde circula e se distribui o ar, quer quente, quer frio, regulando-se a saída dos seus caudais conforme 
as necessidades pontuais de cada compartimento que queiramos tratar.

Estamos perante um sistema de captação de energia que funciona com a máxima segurança, uma vez que apenas utiliza a circulação de água a baixa pressão, conjuntamente com um aditivo anticongelante inofensivo e ecológico, por utilizar um recurso natural inesgotável, a energia da Terra, não poluente, sem combustões, sem fumos nem cheiros e económico como atrás já referimos.

As já referidas tubagens enterradas ligadas em circuito fechado, podem ser utilizadas em três diferentes tipos da captação deste tipo de energia, que são: Captação vertical em que o espaço necessário é reduzido podendo mesmo nalgumas circunstancias ser utilizada a área de implantação dos edifícios; a Captação horizontal em que há necessidade de existir uma área de terreno livre contígua aos edifícios para dispor horizontalmente as tubagens e a Captação em lençol freático em que deve haver uma nascente próxima dos edifícios com um caudal constante. A quantidade de tubagens em qualquer tipo destas captações varia consoante as necessidades energéticas para cada caso concreto.

Quanto à energia solar térmica que está relacionada com o aproveitamento do sol para produzir calor que pode ser usado para o aquecimento de águas, podendo estas servir para utilizar no aquecimento de edifícios, de piscinas, balneários, para usos sanitários, lavagens diversas e ainda ser usada em equipamentos de refrigeração que funcionem através da absorção de calor.

Os Sistemas solares térmicos atualmente instalados na Europa são predominantemente constituídos por uma "caixa metálica", termicamente bem isolada na sua parte posterior, provida de uma cobertura transparente, instalada na sua parte frontal (normalmente com vidro), proporcionando o efeito de estufa no interior do coletor; uma placa metálica de cor escura, que absorverá o máximo de radiação solar, e um conjunto de tubos ligados a esta, no interior, nos quais a água circula e aquece. 
Existem disponíveis no mercado vários tipos de painéis solares térmicos que podem ser aplicados isoladamente em qualquer parte dos edifícios ou integrados como revestimento final de fachadas ou coberturas destes proporcionado assim uma integração perfeita em qualquer tipo de arquitetura. A tecnologia solar térmica existente tem capacidade para produzir e fornecer todas as necessidades de aquecimento, arrefecimento e de águas para os diferentes fins de um qualquer tipo de edifício.

Esta tecnologia tal como outras no âmbito das energias renováveis, está em constante desenvolvimento e por isso os resultados tecnológicos que a curto prazo são esperados, irão melhorar a competitividade da tecnologia e facilitar a expansão do mercado de energia solar térmica. Estas melhorias da tecnologia incluem o desenvolvimento de novos sistemas que irão incorporar coletores superiores com base em materiais poliméricos avançados, o isolamento a vácuo e sofisticados meios de armazenamento de calor, combinado com os controles de gestão inteligente de calor. Esses sistemas poderão ser integrados em edifícios novos, remodelados, ou adaptados, para fornecer águas quentes, aquecimento e arrefecimento.

A energia solar fotovoltaica é aquela que com maior facilidade face ao seu desenvolvimento técnico se pode adaptar para múltiplos tipos de aplicação e uso em qualquer tipo de edifício destinado a Museu.

A energia solar é, sem dúvida, a fonte de energia alternativa mais atraente para o presente e para o futuro pois, para além de ser uma energia limpa e renovável e das suas características de não poluir o ambiente, a sua quantidade disponível para a conversão em energia elétrica é várias vezes superior ao atual consumo energético mundial. São estas as circunstâncias que estão a propiciar a atualidade deste tema e o aproveitamento máximo da radiação solar.

O Sol envia para o nosso planeta inesgotáveis radiações que, sendo aproveitadas usando o equipamento apropriado, fornecerá toda a energia que precisamos. 
Interpretando a palavra "fotovoltaico", (da palavra "photo", significa "Iuz" e o sufixo "voltaico" refere-se à "eletricidade produzida por uma reação química"). A tecnologia fotovoltaica hoje existente e devidamente desenvolvida e permite converter diretamente a energia solar em energia elétrica através de células solares e dos módulos ou painéis fotovoltaicos, e a partir do momento da instalação do processo de produção a energia gerada pode ser consumida diretamente, armazenada em baterias apropriadas ou, lançada diretamente na rede geral de distribuição pública.

Como já referimos a produção de energia elétrica através desta fonte pode obter-se de formas técnicas diferentes, entre elas existe o designado sistema BIPV «Building Integrated Photovoltaics» que consiste na integração de células ou módulos fotovoltaicos na fase de construção em novos edifícios e na fase de remodelação ou reabilitação de edifícios construídos.

Com a utilização deste sistema (BIPV) são garantidas, em simultâneo, várias e importantes funções, como a utilização de elementos estruturais, de revestimento ou de proteção do edifício para a fixação das células fotovoltaicas, e a possível utilização cumulativa de espaços disponíveis para a fixação de módulos fotovoltaicos. Quer as células quer os módulos, podem ser colocados em coberturas, fachadas ou em palas de ensombramento.

Em parte, ou em toda a envolvente dos edifícios construídos ou a construir, podem ser usados módulos transparentes, como os de silício cristalino microperfurado e de silício amorfo transparente, cuja grande vantagem, reside na eventualidade de se for importante considerar para o edifício em concreto, dá-nos a garantia de obter a entrada de uma boa parte da luz natural para dentro do edifício através destes módulos. Existem também disponíveis células fotovoltaicas de variadas cores, sendo possível o seu uso, quer na fabricação dos módulos, quer na aplicação direta sobre os materiais de revestimentos final, e esta diversidade de cores torna-se interessante do ponto de vista de não limitar a imaginação de 
qualquer arquiteto ou designer. Assim, para além da possível auto suficiência em termos de consumos energéticos a partir da produção gerada pelo sistema instalado em cada edifício, poderão ainda ficar com uma moderna imagem arquitetónica.

\section{Conclusões}

As energias aqui referidas são apropriadas para equiparem a curto prazo todos os edifícios de Museus, uma vez que individualmente ou em conjunto proporcionam condições ótimas para a preservação ambiental e em simultâneo contribuem de forma marcante para a sustentabilidade económica no que se refere à energia geotérmica de superfície.

Podemos por vezes, depararmo-nos com situações pontuais em que em alguns edifícios onde funcionam Museus seja difícil implementar qualquer tipo de captação desta energia mas, a grande maioria destes equipamentos culturais localizam-se geralmente em edifícios cuja cave pode facilmente utilizada para esse efeito ou então dispõem de generosos jardins onde, com extrema facilidade, se pode projetar e incorporar esta energia.

A inclusão de qualquer um destes sistemas de captação de energia durante a construção de novos edifícios destinados a Museus, é sem dúvida a melhor solução, o projeto é feito antes do início da construção e os trabalhos de implementação vão avançando com a própria construção do edifício.

As vantagens da utilização desta energia para o aquecimento e arrefecimento dos espaços museológicos e outros, são significativos para qualquer edifício novo, ou existente, que contenha as necessárias condições de aplicação. Uma vez que não produz qualquer tipo de ruído, não tem necessidade de utilizar chaminés para evacuação de cheiros ou gás, proporciona um elevado grau de conforto devido ao seu funcionamento contínuo e não causa qualquer impacto visual negativo.

Quanto à energia solar térmica é muito importante a sua implementação, uma vez que possibilita a instalação individual ou coletiva de sistemas de captação do sol para o aquecimento de 
águas, podendo estas ser utilizadas para consumos correntes necessários em qualquer Museu bem como para aquecimento dos edifícios.

Nos edifícios de Museus, torna-se relativamente fácil a sua implementação, pois a tecnologia disponível adapta-se facilmente a qualquer espaço livre existente com resultados práticos muito satisfatórios. Basta dimensionar as necessidades de águas quentes, escolher o tipo de coletores a instalar, locais disponíveis tendo em conta o enquadramento no local e, os menores percursos das tubagens até ao seu destino final.

Estamos assim, perante uma quase obrigatoriedade de instalar, em qualquer tipo de Museu, esta energia renovável que pode ser sempre complementada por qualquer fonte de energia.

Por fim, a energia solar fotovoltaica é uma das fontes energéticas que tem apresentado um notável desenvolvimento ao longo dos últimos anos. Os sistemas fotovoltaicos têm obtido da comunidade científica e técnica internacional uma enorme atenção e como consequência direta são apontados como uma das grandes oportunidades no setor energético, atualmente e num futuro próximo. Têm características técnicas para poderem ser usados em qualquer tipo de edifício como fonte principal de energia para os seus consumos de eletricidade, nomeadamente com os sistemas BIPV (Building Integrated Photovoltaics).

O avançado desenvolvimento destes sistemas e as tecnologias utilizadas permitem que qualquer edifício os possa incorporar com muita facilidade para a produção de energia elétrica e assim, perante edifícios existentes ou a construir de raiz, podemos optar por colocar os painéis solares na sua cobertura, nas suas fachadas, devidamente integrados ou, num espaço disponível contíguo ou próximo destes.

A variedade de painéis ou módulos solares fotovoltaicos disponíveis no mercado é enorme, desde os mais tradicionais, com menor flexibilidade de integração local, até aos painéis de filmes finos moldáveis a qualquer tipo de superfície onde se pretendam 
aplicar, passando pela integração de células solares em qualquer tipo de envidraçados e de qualquer dimensão.

Acresce ainda a enorme variedade de cores com que os painéis solares fotovoltaicos podem ser acabados, o que, em termos arquitetónicos, é extraordinariamente interessante uma vez que facilita a sua integração em arquiteturas mais ou menos coloridas em qualquer edifício.

Naturalmente que todos os Museus têm as características físicas e condições técnicas para poderem implementar qualquer uma destas fontes energéticas referidas e por isso contribuírem de forma ativa para o bem estar da humanidade. É muito importante o uso massivo destas fontes energéticas para a produção da energia elétrica que consumirem ou, pelo menos uma boa parte dela. $E$, sendo estes tipos de edifícios na grande maioria património público, deveriam dar o exemplo no consumo de energias limpas e renováveis.

\section{Bibliografia}

AA.VV. Planning Successful musem building Projects. EUA: AltaMira Press, 2009.

AA.VV. Buffon Declaration: Disponivel em: http://www.bfn.de/fileadmin/ABS/documents/BuffonDeclarationFi nal\%5B1\%5D.pdf.

Consultado em 18 de fevereiro de 2012.

Agência de Energia \& Instituto Nacional de Engenharia e Tecnologia Industrial. Fórum Energias Renováveis em Portugal, Relatório Síntese. Lisboa: ADENE \& INETI, 2001.

Chagas, Mário.. "O campo de actuação da museologia". Cadernos de Sociomuseologia 2: Lisboa: ULHT, 1994. p. 7-31.

Fuchs, M., Hegger, M., Martin, Z., e Stark, T. Energy Manual: Sustainable Architecture. Darmstadt: Birkh'a'user Architecture, 2008.

Gevorkian, P. Solar Power in Building Design - The engineer's complete design resource. Nova lorque: Mc Graw Hill, 2008. 
Gevorkian, P. Alternative Energy Systems in Building Design. Nova lorque: Mc Graw Hill, 2006.

Gonzalo, R., e Habermann, K. J. Energy-Efficient Architecture - Basics for Planning and Constrution. Darmstadt: Birkh'a'user Architecture, 2006.

Gonçalves, H. Joyce e A. Silva, L. Uma Contribuição para os Objetivos de Política Energética e Ambiental. Lisboa: ADENE/INETI, 2002.

Hestnes, A. G. Hastings, e R. Saxhof, B. Solar Energy Houses Strategies, Technologies, Examples. Londres: James \& James, 2003.

ICOMOS. 1976. Carta de Turismo Cultural. Disponível em: http://www.international.icomos.org/charters.htm. consultado em 6 de junho de 2010.

Lord, Gail Dexter e Lord, Barry. The manual of museum planning. Grã Bretanha: Altamira Press, 2003.

Mendes, M. C. Furtado. O uso de Energias Renováveis em edifícios de Museus. Tese de Doutoramento, Universidade Lusófona de Humanidades e Tecnologias, 2011. Disponível em: http://www.museologia-portugal.net/index.php?option=com content\&view= section \&layout=blog\&id=15\&ltemid=24.

Martin Chivelet, Nuria, e Fernández Solla, Ignacio. La envolvente Fotovoltaica en la arquitectura. Barcelona: Editorial Reverté, SA, 2007.

Mensch, Peter van. Modelos conceituais de museus e sua relação com o patrimônio natural e cultural. ICOFOM-LAM, 1992.

Moutinho, Mário. Autonomia Ritmo e Criatividade na Museologia Contemporânea. Encontros "Linguagens e Processos Museológicos". São Paulo: USP, 2000.

ONU. Declaração sobre as Responsabilidades das Gerações Presentes para com as Gerações Futuras, 1997. Disponível em: http://www.un.org/en/index.shtml. Consultado em 6 de junho de 2010.

Rico, J. C., Los conocimientos Técnicos - Museos Arquitectura Arte. Madrid: Sílex Édiciones,1999. 
Rivière, Georges Henry. La museologia. Madrid: Ediciones Akal, 1993.

Quinteros Panesi, André. Fundamentos de Eficiência Energética Industrial, Comercial e Residencial. São Paulo: Ensino Profissional Editora, 2006.

Serrasolses, J. Tejados Fotovoltaicos - Energia Solar Conectada a la red eléctrica. Sevilha: Progensa, 2004.

UNESCO. Carta de Nairobi, 1976. Disponível em: http://portal.unesco.org/la/conventions_by_country.asp?language= E\&typeconv=1\&contr=PT. Consultado em 2 de setembro de 2011.

UNESCO. Convenção do Património Mundial, Cultural e Natural, 1972. Disponível em:

http://portal.unesco.org/la/conventions by country.asp?language= E\&typeconv=1\&contr=PT. Consultado em 3 de setembro de 2011.

UNESCO. Declaração Universal sobre a Diversidade Cultural, 2001. Disponível em:

http://portal.unesco.org/la/conventions by country.asp?language= E\&typeconv=1\&contr=PT. Consultado em 2 de agosto de 2011.

Varine, Hugues. "L'écomusée". In: Bary, Marie-Odile de; Desvallés, André e Wasserman, Françoise. Dir. 1994. Vagues: une anthologie de la nouvelle muséologie. Paris: MNES, 1978.

Waterfield, P. The Energy Efficient Home - A Complete Guide First published. Marlborough Wiltshire SN8 2HR: Crowood Press Ltd Ramsbury, 2006. 